\title{
Heterogeneous Tissue Modulus Improved Prediction of Mechanical Behavior in Osteoporotic Vertebral Cancellous Bone
}

\author{
Jason M. Cox ${ }^{a}$, Joshua D. Smitha, Marjolein C. H. van der Meulen ${ }^{b}$, Jacqueline H. Cole ${ }^{a}$ \\ ajoint Department of Biomedical Engineering, University of North Carolina, Chapel Hill, NC, and North Carolina \\ State University, Raleigh, NC 27695, United States
}

${ }^{b}$ Meinig School of Biomedical Engineering, Cornell University, Ithaca, NY 14850, United States

J. M. Cox: jmcox9@ncsu.edu

J. D. Smith: jdsmit28@ncsu.edu

M. C. H. van der Meulen: mcv3@cornell.edu

*Corresponding Author, J. H. Cole: jacquecole@ncsu.edu 


\section{Abstract}

The structural integrity of cancellous bone, which is essential to skeletal load-bearing capacity, is governed chiefly by apparent density, trabecular architecture, and tissue material properties. Metabolic bone disorders such as osteoporosis can affect each of these factors separately, resulting in compromised load-bearing function. While the impact of apparent density and architecture on bone mechanical behavior has been well-documented, much less is known about the influence of tissue material properties, particularly in osteoporotic bone. The goal of the present study is to isolate the influence of tissue material properties on the pre-yield mechanical response of normal and osteoporotic cancellous bone to uniaxial compression using finite element (FE) models derived from 3D micro-computed tomography images. Both average tissue material properties and the degree of tissue material heterogeneity vary between individuals. Therefore, three sets of FE models were created to study the relative importance of these two factors: 1) models with material homogeneity within and between subjects, 2) models with material homogeneity within subjects only, and 3) models with material heterogeneity within and between subjects. The results of finite element analyses were compared to data gathered from physical testing with matched conditions. For normal bone, incorporating material heterogeneity within and between subjects had no significant effect on model performance. For osteoporotic bone, incorporating material heterogeneity within subjects did not affect model performance, but models that incorporated subject-specific average material properties were significantly more accurate in replicating the results of physical testing. We conclude that, while the influence of bone apparent density and trabecular architecture on apparent stiffness are dominant in healthy bone, average material properties also play a role in osteoporotic bone. Osteoporosis is diagnosed based on apparent density alone, so our findings suggest a need to consider other patient-specific differences that may affect average tissue material properties, such a bone remodeling rate, in clinical assessments of osteoporotic bone structural integrity.

\section{Introduction}

The structural integrity of cancellous bone, which is essential to skeletal load-bearing capacity, is governed chiefly by apparent density, trabecular architecture, and tissue material properties [1-5]. Although the impact of apparent density and architecture on bone mechanical behavior has been well-documented, much less is known about the influence of tissue material properties. Bone tissue is innately heterogeneous, exhibiting substantial spatial variation in tissue mineral content and quality [6-9]. Osteoporosis affects bone tissue properties, as generally evidenced by altered mineralization and changes in chemical composition [10-13]. Changes in tissue properties may compromise the structural integrity of bone, although the specific contributions of tissue mineralization and composition to bone mechanical properties have not been fully elucidated, particularly for cancellous bone.

Tissue properties are difficult to characterize experimentally and are primarily examined in small, excised bone volumes that likely do not fully capture the in vivo spatial variability. Computer models that simulate a virtual biopsy of cancellous bone can be used to investigate the mechanical behavior of a much larger region of bone and provide the opportunity to analyze that behavior non-invasively over changes in structural and material parameters. Early finite element (FE) models treated cancellous bone as an irregular lattice-type structure and were used to assess the effect of idealized changes in architecture but not tissue properties [14-18]. Architecture-based models, developed by converting voxels from a highresolution micro-computed tomography (micro-CT) scan into cubic finite elements, more closely mimic the bone structure with fewer geometric assumptions than in the lattice models [19]. In the past, these voxel-based models were primarily used to examine the role of architecture in cancellous bone mechanical behavior, and most assumed isotropic and homogeneous material properties [20-30].

Recently, several studies have begun to investigate the effects of incorporating tissue heterogeneity into FE models. Material heterogeneity in bone tissue manifests in variable mineral density $(\rho)$, which is initially low following surfacelocalized bone formation and increases through secondary mineralization as bone tissue matures. Mineral density can be assigned to elements and converted to an elastic modulus $(E)$, a parameter reflecting resistance to deformation, through empirically derived relationships. $E$ - $\rho$ relationships vary across species and bone sites [1,31-34], but generally take a power law form [35]. When derived from density this manner, cancellous bone tissue modulus with increasing variability reduced modulus at the whole bone (or apparent) level and increased the percentage of failed tissue computed by comparing element strains to tissue yield strain [36]. In another study, FE models that approximated realistic in vivo mineral distribution showed a decrease in apparent stiffness up to $4 \%$ with a linear relationship and an increase up to $20 \%$ with a cubic relationship [37]. However, these studies only examined a small volume of cancellous bone (4-5 mm cubic regions) for a small number of samples $(n=3)$, and the findings depended strongly on the assumed mineral distribution [36,37]. 
For a given volume of cancellous bone, calibrated micro-CT scans provide an accurate representation of tissue mineral distribution [38] that can be readily converted into a tissue modulus distribution through empirically derived $E$ - $\rho$ relationships. Studies utilizing this method have shown that incorporating heterogeneous tissue properties mimicking the in vivo distribution improved modulus prediction in rabbits [39] and humans [40] but relied on less clinically relevant sites. Additionally, the study performed in rabbits concluded that specimen-specificity was more important than heterogeneity for improving predictions of apparent stiffness for specimens with low variability in tissue material properties.

Prior work suggests that controlled variability in bone tissue heterogeneity affects the mechanical properties predicted by finite element models. However, studies that extracted heterogeneous material distributions from the samples themselves rather than imposing an assumed distribution do not show a conclusive effect in humans given their choice of a different species [39], a small sample size [41,42], an entirely male cohort [43,44], or a homogeneous control that did not match the average density of the heterogeneous test case [40]. Therefore, the question remains open as to whether physiological heterogeneity in FE models and by extension, in vivo, has a substantial influence on cancellous bone apparent properties. In addition, it is not fully understood how the influence of heterogeneity depends on sex or the presence of metabolic bone disorders such as osteoporosis. Given that osteoporosis alters bone mineralization and the disparity in the instance of osteoporosis between sexes, examining these parameters need to be examined if the robustness of $\mathrm{FE}$ models is to be established. The objectives of this study were 1) to simulate the mechanical behavior of cancellous bone in the human spine using specimen-specific architecture- and material-based FE models, 2) to assess the effects of varied material models on the mechanical performance of the bone structure, 3) to compare model-derived parameters to experimentally measured mechanical properties of the cancellous specimens, and 4) to determine the effects of sex and clinical bone status on the mechanical properties of the cancellous specimens across the various material models. Our approach was to model the architecture and material variations of human vertebral cancellous bone based on micro-CT scans and to compare the model predictions for different material distributions to experimentally measured mechanical properties of the same specimens.

\section{Materials and Methods}

\subsection{Subjects}

Cadaver spine segments were obtained from 21 Caucasian donors ( 11 female, 10 male) aged 56 to 92 years. For 20 donors, the spine segment extended from the $11^{\text {th }}$ thoracic vertebra (T11) through the 4th lumbar vertebra (L4), and for one donor, the segment extended from T11 through the 2nd lumbar vertebra (L2). None of these spines showed evidence of vertebral fracture in a clinical bone density scan or of bone abnormalities during dissection, such as bone metastasis.

\subsection{Clinical Bone Density Scan}

Clinical bone mineral density status was assessed for all donors with dual-energy X-ray absorptiometry (DXA). Spine segments were secured in a curved Plexiglas ${ }^{\circledR}$ fixture, immersed in a saline bath within a Plexiglas ${ }^{\circledR}$ box, and scanned with a clinical fan-beam densitometer in lumbar spine array mode (Delphi QDR 4500A or QDR 4500W, Hologic Inc., Bedford, MA). T-score was computed for the L1-L4 subregion of each spine using the Hologic analysis software, and subjects were classified by T-score, according to the World Health Organization guidelines [45], as Non-osteoporotic (T-score $>-2.5)$ and Osteoporotic (T-score $\leq-2.5)$.

\subsection{Micro-Computed Tomography Scan}

To prepare a small cancellous bone specimen for micro-CT, the $L 2$ vertebra was excised from each spine segment, and a full-depth cylindrical specimen (diameter $=8.25 \mathrm{~mm}$ ) was obtained from the center of the vertebra. The vertebra was secured in a drill press, and the cut was made along the superior-inferior axis at low speed under a continuous saline stream using a metal bond diamond core drill (Starlight Industries, Rosemont, PA). Cored specimens were wrapped in saline-soaked gauze and stored frozen at $-20^{\circ} \mathrm{C}$ until scanning.

To obtain a voxel-based characterization of cancellous bone structure and mineralization, cored vertebral specimens were scanned using quantitative micro-CT (MS-8, GE Healthcare, London, Ontario, Canada) with $70 \mathrm{kVp} \mathrm{X-ray} \mathrm{tube} \mathrm{peak}$ potential, $90 \mu \mathrm{A} \mathrm{X}$-ray intensity, and $3 \mathrm{~s}$ integration time. The specimens were scanned in saline treated with a protease inhibitor cocktail to minimize protein degradation in the bone tissue (P8340, Sigma-Aldrich Inc., St. Louis, MO) and then refrozen at $-20^{\circ} \mathrm{C}$ until mechanical testing. The scans were reconstructed at an isotropic voxel size of $17.0 \mu \mathrm{m}$, and mineral density was calibrated using a phantom consisting of air, water, and a bone mineral standard (SB3, Gammex RMI, 
Middleton, WI) with a known density of $1.15 \mathrm{~g} / \mathrm{cc}$. For analysis, the scans were reoriented to align the superior-inferior axis of the core with the vertical axis in the manufacturer's software, and the ends of the cores were then cropped flat to a length of $17 \mathrm{~mm}$ (MicroView ABA 2.1.1., GE Healthcare, London, Ontario, Canada). Past work has suggested that the use of a global segmentation threshold for a cohort with a broad range of bone volume fraction or varying bone mineral density can result in an inaccurate topology [46]. To account for the inclusion of both osteoporotic and non-osteoporotic subjects in our cohort, specimen-specific thresholds were determined in the software using the Otsu method [47]. Bone volume fraction (BV/TV) and tissue mineral density (TMD) were assessed for each core.

\subsection{Mechanical Testing}

Following micro-CT scans, the cancellous bone cores were tested destructively in uniaxial compression, and apparentlevel properties were assessed to validate the FE models. After the cortical end plates were removed, the bone core ends were glued inside snug-fitting brass caps using a previously documented protocol designed to minimize end artifacts [48]. Approximately one-fourth of the overall core length was capped at each end. The diameter of each cancellous core was measured six times, and the exposed length was measured four times, using metric dial calipers, and the mean values were recorded. After the cyanoacrylate glue was cured for 24 hours at $4^{\circ} \mathrm{C}$, the capped cores were preconditioned for 5 cycles between 0 and $0.10 \%$ compressive strain and then loaded monotonically to failure at a rate of $-0.50 \%$ strain per second (Mini-Bionix 858, MTS Systems Corporation, Eden Prairie, MN). Tests were conducted in displacement control at room temperature, and load and displacement data were sampled at $20 \mathrm{~Hz}$. Displacement was measured with a $25-\mathrm{mm}$ gage length axial extensometer (634.11F-24, MTS Systems Corporation, Eden Prairie, MN) attached to both brass caps. To compute apparent mechanical properties, load and displacement data were converted to apparent stress and strain using standard mechanics formulae [49]. The experimental apparent modulus was defined as the slope of a least-squares linear fit to the elastic region of the stress-strain data over $0.02-0.24 \%$ strain [50].

\subsection{Finite Element Modeling}

The micro-CT scans were used to build specimen-specific finite element (FE) models for all of the bone cores [20,30]. Using the thresholded micro-CT scans, bone voxels were converted into 8-node linear brick elements, creating FE meshes measuring approximately $8.25 \mathrm{~mm}$ in diameter and $17 \mathrm{~mm}$ in length (Figure 1a, 1b). Elements unconnected to the primary structure were removed using the connectivity criterion of a 6-connected neighborhood. Unless an element shared a face with a portion of the primary bone structure, it was considered unconnected and was removed from the model. For all models, the number of unconnected elements removed was between $0.6 \%$ and $7.6 \%$ of the total number of elements. On average, the final FE models had $24,000,000$ elements and 33,000,000 nodes, for a total of 79,000,000 degrees of freedom.

Three sets of FE models were created for each bone core using different material properties. For each set, the models were assigned isotropic material properties with a constant Poisson's ratio of 0.3 and one of the following three tissue modulus distributions:

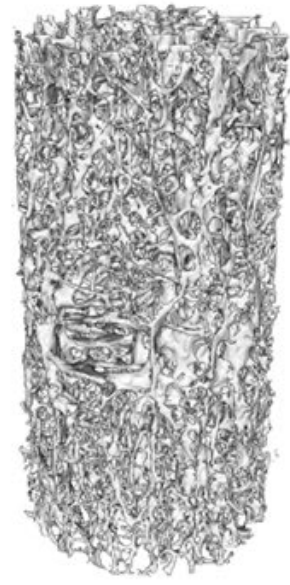

a) Non-Osteoporotic, (M77T)
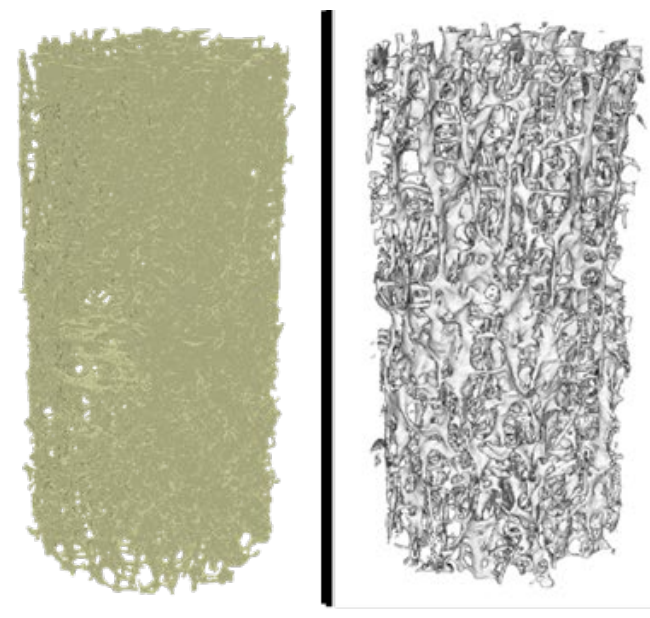

b) Osteoporotic, (F87T)

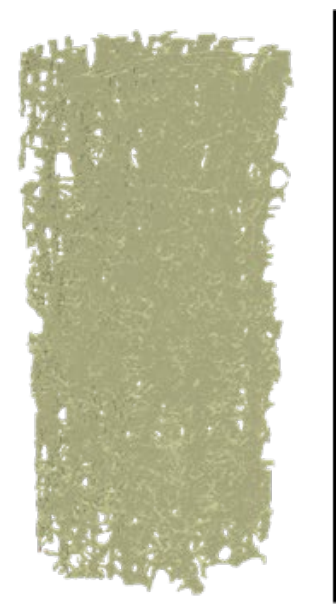

c) Boundary Conditions

Figure 1: Examples of reconstructed volumes and finite element meshes (bottom) for (a) non-osteoporotic, and (b) osteoporotic subjects. Sex (M/F), age in years and vertebral site (thoracic) are denoted. (c) Boundary conditions for finite element models. A compressive strain of $0.25 \%$ was applied to nodes on the top surface of the mesh. Nodes on the bottom surface were constrained to in-plane motion, barring two adjacent nodes on the edge which were completely constrained to prevent rigid-body motion. 
1. Universal Homogeneous ( $U_{\text {hom }}$ ): A single homogeneous modulus of $20 \mathrm{GPa}$, chosen based on measurements from nanoindentation studies, was assigned to all elements for all bone core models.

2. Specimen-Specific Homogeneous (SShom): A unique homogeneous modulus was applied to all elements of each bone core model, computed using the voxel mineral content from micro-CT scans and a linear modulus-density relationship [1], as follows:

$$
E=E_{c}\left(\frac{\rho_{\text {mean }}}{\rho_{c}}\right)^{b}
$$

where $E_{c}$ is the compressive tissue modulus for fully mineralized cortical bone (defined as $20 \mathrm{GPa}$ ), $\rho_{\text {mean }}$ is the mean apparent density over all mineralized voxels of the bone specimen, $\rho_{c}$ is the apparent density of the SB3 cortical bone mineral standard, and $b$ is the exponent defining the nature of the E- $\rho$ relationship (i.e., $b=1$ for $a$ linear relationship). Assuming a linear relationship between apparent density and CT attenuation values, $\rho_{\text {mean }} / \rho_{c}$ ratio was computed using the ratio of the mean CT attenuation value to the SB3 mineral standard CT value.

3. Specimen-Specific Heterogeneous ( $S S_{\text {het }}$ ): $A$ unique heterogeneous modulus was computed for each element within each bone core model, using the same linear $E$ - $\rho$ formula, except $\rho_{\text {mean }}$ was replaced by the individual voxel apparent density $\rho_{\text {vox }}$, and $E$ was computed individually for each element using the CT value for the associated voxel. Element moduli were then grouped into 1000 equally spaced bins to simplify the assignment of material properties while maintaining ample variability.

To prevent scanning artifacts, which appear as abnormally high-density regions of the bone, ranges of measured tissue density for each model were computed and normalized to the value of $\rho_{c}$. These ranges were used to determine a global upper threshold of relative tissue density, and voxels with tissue densities above this threshold were assigned the mean value of tissue densities computed from the remaining voxels. Less than $0.002 \%$ of elements in only three models were affected. Applying this correction prevented scanning artifacts from artificially decreasing the degree of heterogeneity in the models by increasing the width of element modulus bins.

Boundary conditions were applied to the models to replicate displacement-controlled uniaxial compressive loading in the linear elastic range (Figure 1c). Pre-yield compression was simulated by displacing the nodes on the top surface of the cancellous core mesh to a strain of $-0.25 \%$. The nodes on the bottom surface of the mesh were treated as rollers constrained to in-plane motion only, and two adjacent nodes at one edge of the bottom surface were rigidly fixed to prevent rigid-body motion. The FE models were solved using a linear elastic static analysis (ABAQUS 6.3, HKS, Pawtucket, $\mathrm{RI}$ ), and two outcome parameters were examined, the model-predicted apparent modulus and the distribution of minimum principal strains throughout the bone structure. The apparent modulus was calculated by summing the nodal reaction forces on the bottom surface of the core mesh and dividing by the cross-sectional area of a circle enclosing that surface. Minimum principal strain $\left(\epsilon_{1}\right)$ was analyzed at the element centroids throughout the model, and values were categorized as low ( $\epsilon_{1}<500$ microstrain), moderate (500 microstrain $\leq \epsilon_{1}<1500$ microstrain), or high $\left(\epsilon_{1} \geq 1500\right.$ microstrain) strain. The median was used in lieu of the mean due to the distinct negative skew of the $\epsilon_{1}$ distributions.

\subsection{Statistical Analyses}

First, the effects of apparent modulus estimation method (i.e., mechanical testing and three sets of models), sex, and osteoporosis status on apparent modulus and minimum principal strain were investigated with mixed linear models. Second, the effect of modulus estimation method on apparent modulus and minimum principal strain was investigated with linear models for subsets of the cohort separated by sex, site, and osteoporosis status, using the Hochberg correction to account for multiple comparisons generated by multiple linear models [51] and Tukey-Kramer correction for posthoc pairwise comparisons between the four methods. Finally, to evaluate the impact of categorical variables alongside finite element estimated modulus in predicting experimental modulus, mixed linear regression models were constructed. To correct for each donor spine being represented twice in the dataset, donor ID was incorporated in the mixed linear models as a random intercept effect. A significance level of 0.05 was used for all analyses (SAS 9.4, SAS Institute Inc., Cary, NC). 
bioRxiv preprint doi: https://doi.org/10.1101/2021.11.30.470675; this version posted December $1,2021$. The copyright holder for this preprint (which was not certified by peer review) is the author/funder, who has granted bioRxiv a license to display the preprint in perpetuity. It is made available under aCC-BY 4.0 International license.

\section{Results}

CT-based finite element models were developed for thoracic and lumbar vertebral cancellous bone cores of 19 subjects of both sexes, aged 58-92, with a broad range of DXA T-score (Table 1). For two subjects, models were built but the analyses could not complete on the available hardware due to these models having exceptionally high DOFs. Bone volume fraction of the vertebral cores measured from micro-CT scans at a resolution of $17 \mu \mathrm{m}$ varied greatly from $5.8 \%$ to $14.1 \%$, with a coefficient of variation (COV) of $21 \%$. No significant differences in bone volume fraction were observed by vertebral sex $(p=0.33)$, or by site $(p=0.33)$. Tissue BMD varied slightly less, ranging from 0.5 to 1.2 $\mathrm{g} / \mathrm{cc}$, with a COV of $15 \%$. The distribution of tissue mineral throughout the meshed bone volume, as assessed by normalized CT attenuation, differed somewhat between subjects, with a coefficient of variation ranging from $18.4 \%$ to $37.0 \%$. The variation did not appear to relate to sex, vertebral site, or clinical bone diagnosis (Figure 2).

For models with specimen-specific heterogeneous material properties, the distribution of bone tissue modulus was identical to that of tissue mineral density given their linear relationship, and similar in shape for all subjects (Figure 2). Though no relationship was found between apparent modulus measured through destructive testing and mean tissue modulus $(p=0.54)$ or tissue modulus variability $(p=0.56)$, a positive correlation was found between bone volume fraction and measured apparent modulus $(p=$ 0.02). Overall, the heterogeneous tissue modulus averaged 14.5-22.1 GPa over all elements for a given model, yielding a global mean of $18.2 \mathrm{GPa}$ over all models (Table $\mathbf{1}$ ).

Table 1: Mean tissue modulus for specimen-specific heterogeneous and homogeneous models. Modulus for universal homogeneous models equals 20 GPa.

\begin{tabular}{|c|c|c|c|c|c|c|c|c|c|}
\hline \multirow{2}{*}{\multicolumn{2}{|c|}{$\operatorname{Sex} A$}} & \multirow{2}{*}{$\begin{array}{l}\text { L1-L4 T- } \\
\text { score }\end{array}$} & \multirow{2}{*}{$\begin{array}{c}\text { Bone } \\
\text { Diagnosis }\end{array}$} & \multicolumn{2}{|c|}{ Tissue Mod (Gpa) } & \multicolumn{4}{|c|}{ Mean Apparent Mod (GPa) } \\
\hline & Ige & & & Bone Site & Mean $(\mathrm{SD})^{+}$ & $E_{\text {exp }}$ & $U_{\text {hom }}$ & $\mathrm{SS}_{\text {hom }}$ & $\mathrm{SS}_{\text {het }}$ \\
\hline \multirow{2}{*}{$\mathrm{F}$} & \multirow{2}{*}{74} & \multirow{2}{*}{-0.8} & \multirow{2}{*}{ Normal } & Thoracic & $20.5(4.3)$ & 0.51 & 0.55 & 0.56 & 0.56 \\
\hline & & & & Lumbar & $20.0(4.5)$ & 0.84 & 0.86 & 0.87 & 0.86 \\
\hline \multirow{2}{*}{$\mathrm{M}$} & \multirow{2}{*}{77} & \multirow{2}{*}{-0.8} & \multirow{2}{*}{ Normal } & Thoracic & $20.2(4.3)$ & 0.62 & 0.62 & 0.63 & 0.62 \\
\hline & & & & Lumbar & $20.2(4.5)$ & 0.34 & 0.34 & 0.35 & 0.33 \\
\hline \multirow{2}{*}{$\mathrm{M}$} & \multirow{2}{*}{65} & \multirow{2}{*}{-1.2} & \multirow{2}{*}{ Osteopenia } & Thoracic & $15.3(4.2)$ & 0.58 & 0.60 & 0.46 & 0.45 \\
\hline & & & & Lumbar & $15.2(4.6)$ & 0.55 & 0.67 & 0.51 & 0.50 \\
\hline \multirow{2}{*}{$\mathrm{M}$} & \multirow{2}{*}{79} & \multirow{2}{*}{-1.2} & \multirow{2}{*}{ Osteopenia } & Thoracic & $21.1(4.2)$ & 0.63 & 0.64 & 0.68 & 0.67 \\
\hline & & & & Lumbar & $20.9(4.3)$ & 0.48 & 0.49 & 0.51 & 0.49 \\
\hline \multirow{2}{*}{$\mathrm{F}$} & \multirow{2}{*}{58} & -15 & Osteonenia & Thoracic & $20.7(4.4)$ & 0.93 & 0.89 & 0.92 & 0.91 \\
\hline & & -1.5 & Usteopenia & Lumbar & $21.9(4.2)$ & 0.73 & 0.62 & 0.67 & 0.67 \\
\hline$M$ & 71 & -16 & Osteonenia & Thoracic & $20.3(4.5)$ & 0.56 & 0.64 & 0.65 & 0.65 \\
\hline IVI & $7 \perp$ & -1.0 & Usteuperila & Lumbar & $19.8(4.9)$ & 0.66 & 0.80 & 0.79 & 0.78 \\
\hline$M$ & 67 & -1.7 & Osteopenia & Thoracic & $16.0(4.4)$ & 0.71 & 0.48 & 0.39 & 0.39 \\
\hline IVI & 01 & -1.7 & Usteopenid & Lumbar & $15.9(4.7)$ & 0.48 & 0.69 & 0.55 & 0.54 \\
\hline$M$ & 63 & -18 & Octeonenia & Thoracic & $19.1(4.6)$ & 0.39 & 0.48 & 0.45 & 0.44 \\
\hline IVI & 03 & -1.8 & Usteopenid & Lumbar & $20.0(4.5)$ & 0.55 & 0.50 & 0.50 & 0.48 \\
\hline $\mathrm{F}$ & 61 & -19 & Osteonenia & Thoracic & $20.7(4.7)$ & 0.60 & 0.59 & 0.61 & 0.61 \\
\hline$r$ & 01 & -1.5 & Usteuperiad & Lumbar & $19.0(4.9)$ & 0.59 & 0.55 & 0.52 & 0.51 \\
\hline$M$ & 63 & 22 & Octeonenia & Thoracic & $21.9(4.2)$ & 0.70 & 0.66 & 0.73 & 0.73 \\
\hline IVI & 03 & -2.2 & Usteupenid & Lumbar & $22.1(4.1)$ & 0.77 & 0.66 & 0.73 & 0.73 \\
\hline$M$ & 69 & -23 & Osteopenia & Thoracic & $15.2(5.3)$ & 0.32 & 0.55 & 0.42 & 0.39 \\
\hline & & & & Lumbar & $15.5(5.1)$ & 0.35 & 0.45 & 0.35 & 0.34 \\
\hline $\mathrm{F}$ & 92 & -2.6 & Osteoporosis & Thoracic & $20.0(4.3)$ & 0.38 & 0.52 & 0.52 & 0.51 \\
\hline$r$ & 92 & -2.0 & Usteoporosis & Lumbar & $19.6(4.7)$ & 0.47 & 0.48 & 0.47 & 0.46 \\
\hline$M$ & 64 & -29 & Osteonorosis & Thoracic & $14.8(4.6)$ & 0.28 & 0.62 & 0.46 & 0.44 \\
\hline IVI & 04 & -2.9 & Usteoputusis & Lumbar & $18.4(4.6)$ & 0.60 & 0.72 & 0.67 & 0.64 \\
\hline $\mathrm{F}$ & 61 & $-32+2$ & Osteonorosic & Thoracic & $18.2(4.9)$ & 0.45 & 0.49 & 0.45 & 0.44 \\
\hline$r$ & 01 & -3.2 & Usteoputusis & Lumbar & $19.7(4.8)$ & 0.45 & 0.44 & 0.43 & 0.42 \\
\hline $\mathrm{F}$ & 87 & -3.5 & Osteoporosis & Thoracic & $19.0(4.7)$ & 0.12 & 0.38 & 0.36 & 0.36 \\
\hline & & & & Lumbar & $19.5(4.5)$ & 0.43 & 0.38 & 0.37 & 0.37 \\
\hline $\mathrm{F}$ & 87 & -3.8 & Osteoporosis & Thoracic & $18.9(4.7)$ & 0.37 & 0.51 & 0.48 & 0.47 \\
\hline $\mathrm{F}$ & 81 & -3.8 & Usteoporosis & Lumbar & $19.9(4.4)$ & 0.40 & 0.34 & 0.34 & 0.33 \\
\hline $\mathrm{F}$ & 68 & -3.9 & Osteoporosis & Thoracic & $14.8(4.6)$ & 0.11 & 0.26 & 0.20 & 0.18 \\
\hline & & & & Lumbar & $14.5(5.4)$ & 0.17 & 0.52 & 0.38 & 0.37 \\
\hline $\mathrm{F}$ & 65 & -4.4 & Osteonorosic & Thoracic & $15.5(4.6)$ & 0.33 & 0.46 & 0.36 & 0.34 \\
\hline$r$ & 03 & -4.4 & Usteoporosis & Lumbar & $15.3(4.2)$ & 0.29 & 0.36 & 0.27 & 0.26 \\
\hline $\mathrm{F}$ & 79 & -52 & Osteonorosis & Thoracic & $16.0(5.7)$ & 0.42 & 0.54 & 0.44 & 0.43 \\
\hline 1 & & & 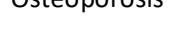 & I umbar & $159(5))$ & 020 & 029 & $0>3$ & 073 \\
\hline
\end{tabular}

Uniform compressive strain was applied to the top surface of the cancellous core models, and the apparent elastic moduli were computed for the structure (Figure 3). The range of predicted apparent modulus was 0.26-1.27 GPa for $\mathrm{U}_{\text {hom }}$ models, 0.20-0.92 GPa for $\mathrm{SS}_{\text {hom }}$ models, and 0.18-0.91 GPa for $\mathrm{SS}_{\text {het }}$ models (Table 1, Figure 4). Apparent modulus for the cancellous bone cores as measured through destructive uniaxial compression testing ranged from 0.11-0.93 GPa. Preliminary analyses using mixed models with full effects revealed that interactions between measurement method, sex, vertebral site, and clinical bone status were not significant, so these effects were removed from all subsequent analyses. Mean finite element-predicted apparent modulus across all subjects was not significantly different from mean measured apparent modulus for any of the three assigned distributions. Regardless of the estimation method, apparent modulus differed by clinical bone diagnosis ( $p=0.008$, Figure 4). Furthermore, when separating the subjects by clinical bone diagnosis, $U_{\text {hom }}$ models displayed a significantly higher mean apparent modulus than the measured mean among 
osteoporotic subjects ( $p=0.045$, Figure 4). Although apparent modulus tended to be slightly lower in females than in males across estimation methods, this effect was not significant. $(p=0.96)$.

(a)

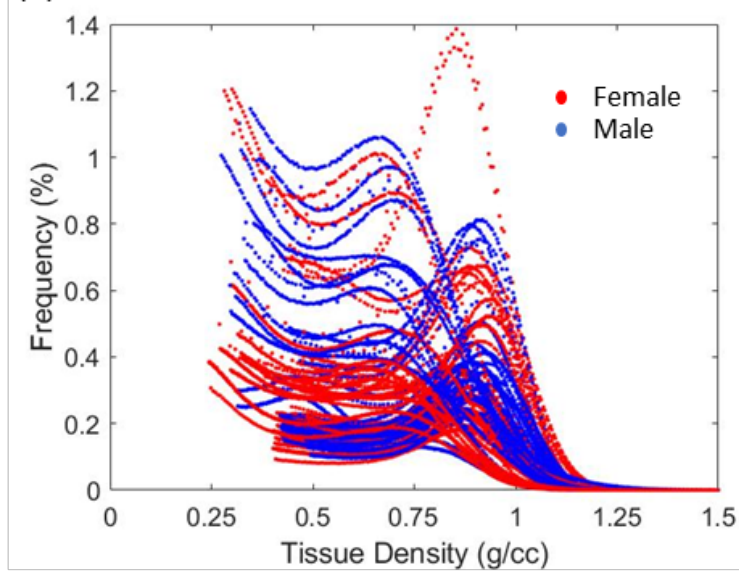

(b)

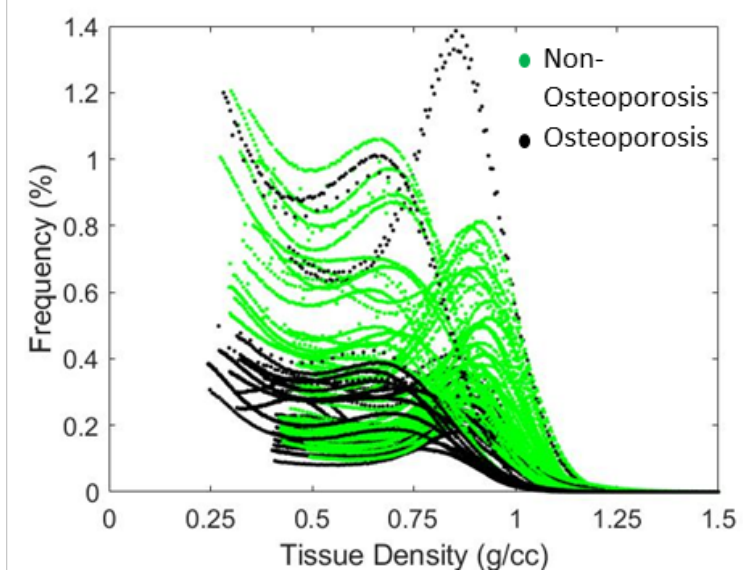

Figure 2: Bone tissue mineral distribution assessed using CT attenuation for all 21 subjects, separated by (a) sex and (b) clinical bone diagnosis. Shown are the percentages of voxels for each CT attenuation value, normalized by the CT value for the cortical bone phantom and scaled by its density $(1.15 \mathrm{~g} / \mathrm{cc})$. The voxel densities shown here are only those above the bone threshold for each subject.

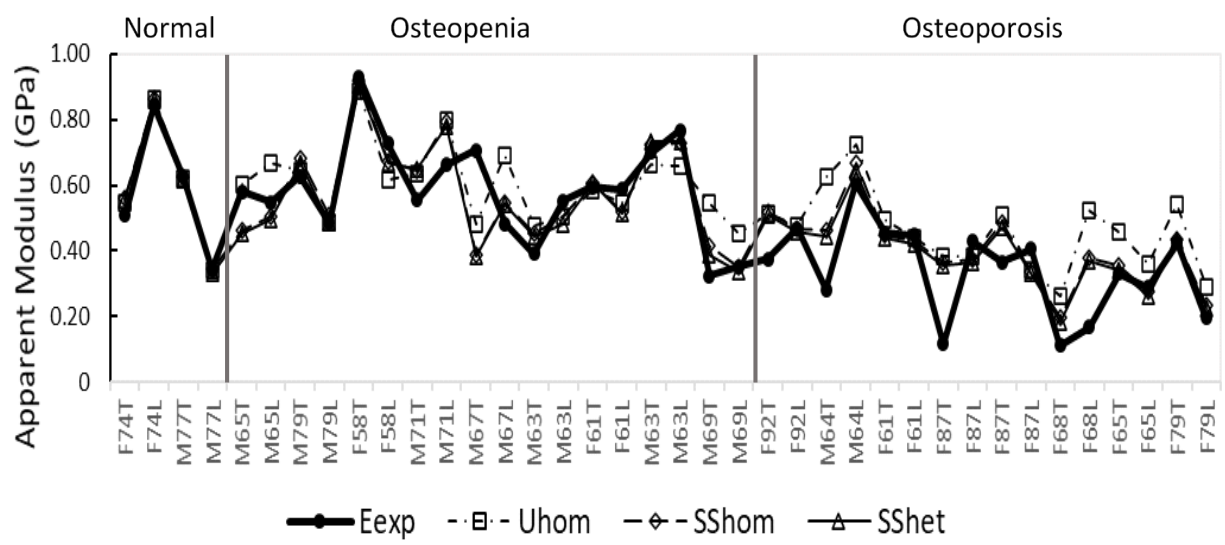

Figure 3: Apparent modulus from finite element models closely predicted experimentally measured values, regardless of tissue moduli assigned. Subjects are denoted by sex $(M=$ male, $F=$ female), age in years, and vertebral site $(\mathrm{T}=$ thoracic, $\mathrm{L}=$ Lumbar).

There were no significant differences in modulus prediction error across all subjects by modulus distribution, nor were there differences when segmenting the dataset by the parameters sex, bone site, or clinical osteoporosis status. Within $U_{\text {hom }}$ models however, modulus prediction error was $50 \%$ greater on average for osteoporotic specimens compared to non-osteoporotic specimens $(p=0.04)$, with a strong tendency towards overestimation $(p=0.0009)$. Specimen-specific models did not indicate a difference in modulus prediction error by clinical bone diagnosis $(p=0.52$ for homogeneous, $p=$ 0.67 for heterogeneous) or a tendency towards overestimation for osteoporotic specimens ( $p=0.10$ for homogeneous, $p$ $=0.21$ for heterogeneous). For each of the three model sets, modulus prediction error decreased with increasing experimentally measured modulus, following a negative power law relationship (Figure 5).

Regardless of assigned modulus distribution, FE-predicted modulus was linearly related to the experimental apparent modulus ( $p<0.0001$ for all cases) (Figure 6a). Overall, specimen-specific models predicted apparent modulus more accurately than $U_{\text {hom }}$ models. The coefficient of determination for universal models (0.61) indicated a moderate amount of fit to the experimental data, but the coefficient of determination for specimen-specific models ( 0.74 for homogeneous and 0.75 for heterogeneous) indicated a substantially better fit. Among the categorical variables sex, site, and clinical bone diagnosis, only clinical bone diagnosis was significant in a mixed linear regression model with FE-predicted modulus. 
Incorporating clinical bone diagnosis improved the coefficient of determination by $13 \%$ for universal models and $5 \%$ for both specimen-specific model sets (Figure 6b).

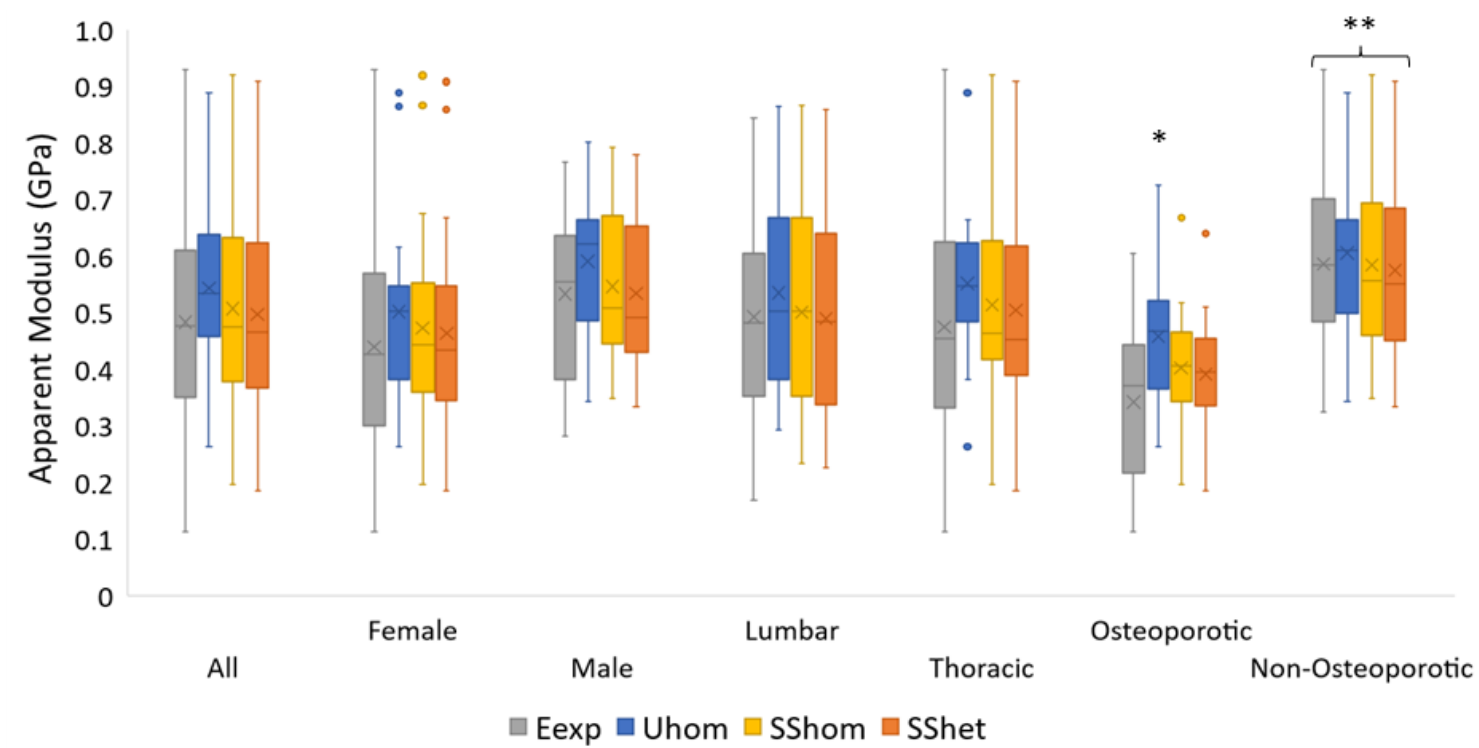

Figure 4: Apparent modulus for each measurement method, shown for all subjects, separated by sex, site, and clinical bone diagnosis. ${ }^{*} p<0.05$ vs. Eexp within osteoporotic group, ${ }^{* *} p<0.05$ vs. osteoporotic group.

Distributions of compressive minimum principal strain $(\varepsilon 1)$ were evaluated throughout the model (Figure 7). Because the $\mathrm{FE}$ analyses were linear and displacements were applied, the results for $\varepsilon 1$ were identical in both sets of homogeneous models (i.e., universal and specimen-specific). Therefore, only the results for universal homogeneous and specimenspecific heterogeneous models were evaluated. A $14 \mathrm{~mm}$ central volume of interest (VOI) was initially considered for analysis in order to prevent inflated strains in elements near to the applied load from strongly affecting the results, similar to end-artifacts previously described in mechanical compression testing of bone between platens [52]. However, no significant difference in the proportion of high-strain elements was found between a full-size model and a central $14 \mathrm{~mm}$ VOI for homogeneous and heterogeneous models $(p=0.2,0.9$ respectively). Therefore, all elements were included for strain analyses. Because the distributions of $\varepsilon 1$ had a distinct negative skew, with most of the values concentrated near zero, the median was used as the measure of centrality in lieu of the mean. For clarity, values of compressive strain will be discussed in terms of the absolute value.

Distributions of $\varepsilon 1$ were similar for homogeneous and heterogeneous material models (Figure 7). Across subjects there were no differences in median $\varepsilon 1$ by modulus distribution, sex, or clinical bone status. Median $\varepsilon 1$ did differ by bone site $(p<0.0001)$, with thoracic models having higher median $\varepsilon 1$ than lumbar models by 98 microstrain (Figure 8). When segmenting the dataset by bone site, a difference in median $\varepsilon 1$ by modulus distribution was found in lumbar models, with homogeneous models displaying a higher median $\varepsilon 1$ than heterogeneous models by 92 microstrain ( $p=0.009$, Figure 8). The spread of $\varepsilon 1$ throughout the models did not differ by any of the investigated parameters ( $p=0.92$ for $\mathrm{SD})$. For homogeneous models, the proportions of strain values in the discrete categories of low, medium and high strain were $37 \%, 41 \%$ and $22 \%$, respectively (Figure 9). Likewise, for heterogeneous models, respective proportions of low, medium and high strain values were $39 \%, 40 \%$ and $21 \%$. Though differences by assigned modulus distribution were significant for proportions of low strain $(p=0.04)$ and high strain $(p=0.009)$

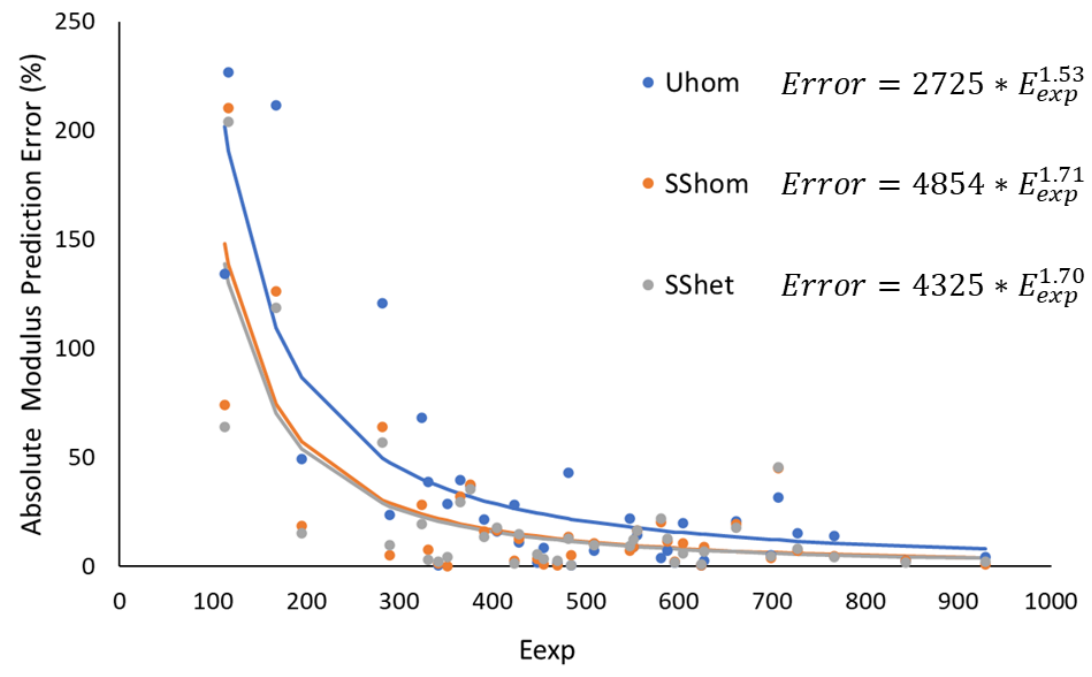

Figure 5: Absolute modulus prediction error for each model set, expressed as a percentage difference from the Eexp. Data follow a negative power law trend. 
among lumbar specimens, these differences were very small and any appreciable effects on the mechanical behavior of the models is doubtful.

\section{Discussion}

In architecture-based finite element models of human vertebral cancellous bone, specimen-specific tissue moduli substantially improved the overall prediction of apparent stiffness compared to models that assumed material homogeneity within and between subjects. Finite element models incorporating intra-specimen material heterogeneity performed only marginally better than specimen-specific homogeneous models. The crucial factor in improving model performance - specimen-specificity or heterogeneity - is disputed [39-44], although our results appear to support specimen-specificity. However, the assumption of purely elastic or linear deformation in FE models of cancellous bone may limit the efficacy of incorporating heterogeneity since linear behavior at the apparent level in vivo may involve some nonlinear behavior at the tissue level. The beam-like structure of trabeculae entails that high strains beyond the upper elastic threshold are likely to occur near the surface of bending trabeculae. Low-density bone tissue also tends to be found at the trabecular surface, owing to surface-localized bone remodeling [53]. The inverse distributions of strain magnitude and mineral density throughout the trabecular cross-section may indicate an important relationship between nonlinear behavior at the tissue level and tissue heterogeneity. Therefore, linear FE analyses may suppress the effects of incorporating heterogeneity in FE models.

Despite this limitation, our investigation of $\varepsilon 1$ distributions in lumbar models revealed that incorporating material heterogeneity did have some effect at the microstructural level. Homogeneous lumbar models had a higher median $\varepsilon 1$ than heterogeneous models as well as a higher apparent modulus. Additionally, for 17 out of 19 lumbar bone cores, heterogeneous models had a higher maximum $\varepsilon 1$. These results suggest that homogeneous models had a greater number of medium and high strain elements despite having a greater resistance to overall strain. A function of cancellous bone material heterogeneity may therefore be to concentrate deformations in small regions of the microstructure. Previous work has suggested that trabeculae oriented
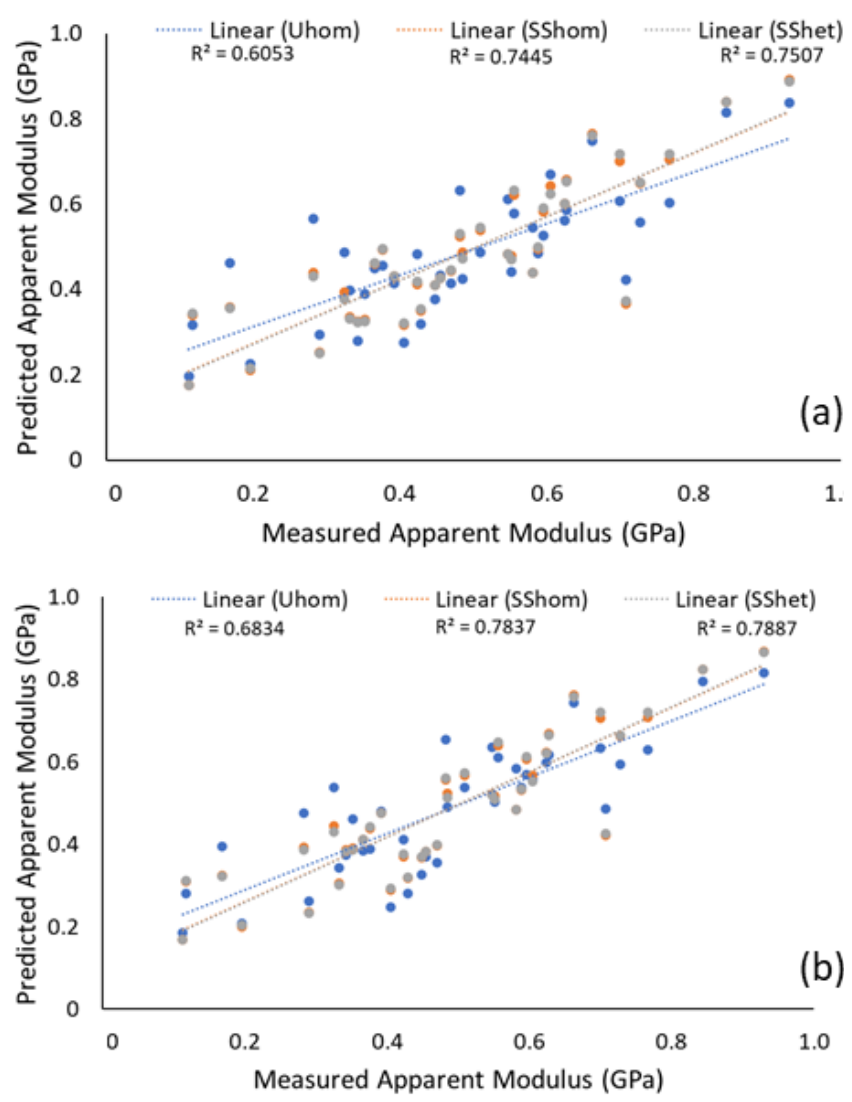

Figure 6: Specimen-specific (SS) heterogeneous and homogeneous finite element models improved prediction of experimentally measured apparent modulus compared to universal homogeneous models (a). Including clinical bone diagnosis as an explanatory variable improved $r^{2}$ for all three model sets (b).
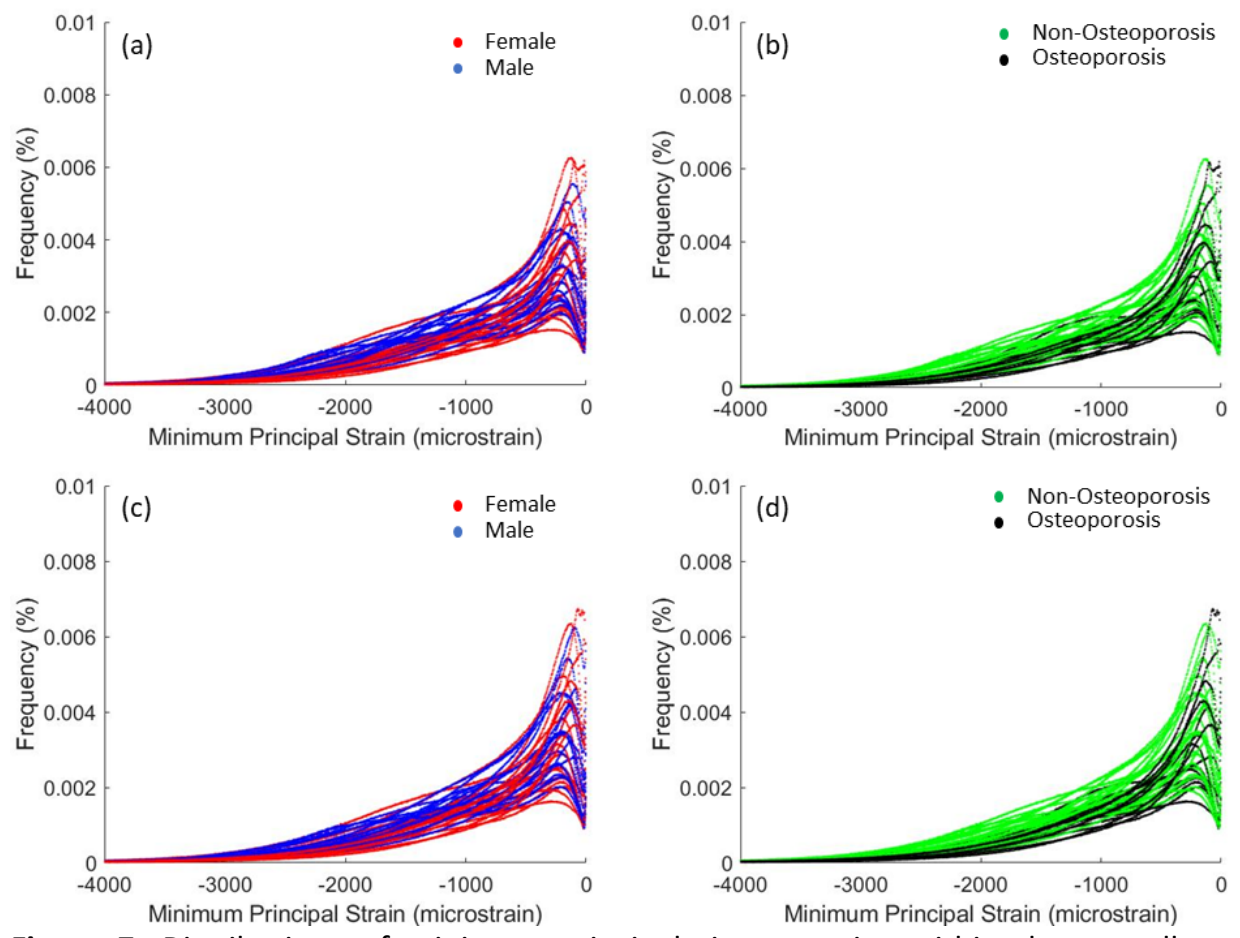

Figure 7: Distributions of minimum principal tissue strains within the cancellous microstructure for samples with universal homogeneous $(a, b)$ and specimen-specific heterogeneous $(c, d)$ material properties for all subjects, separated by sex $(a, c)$ and clinical bone diagnosis $(b, d)$. 


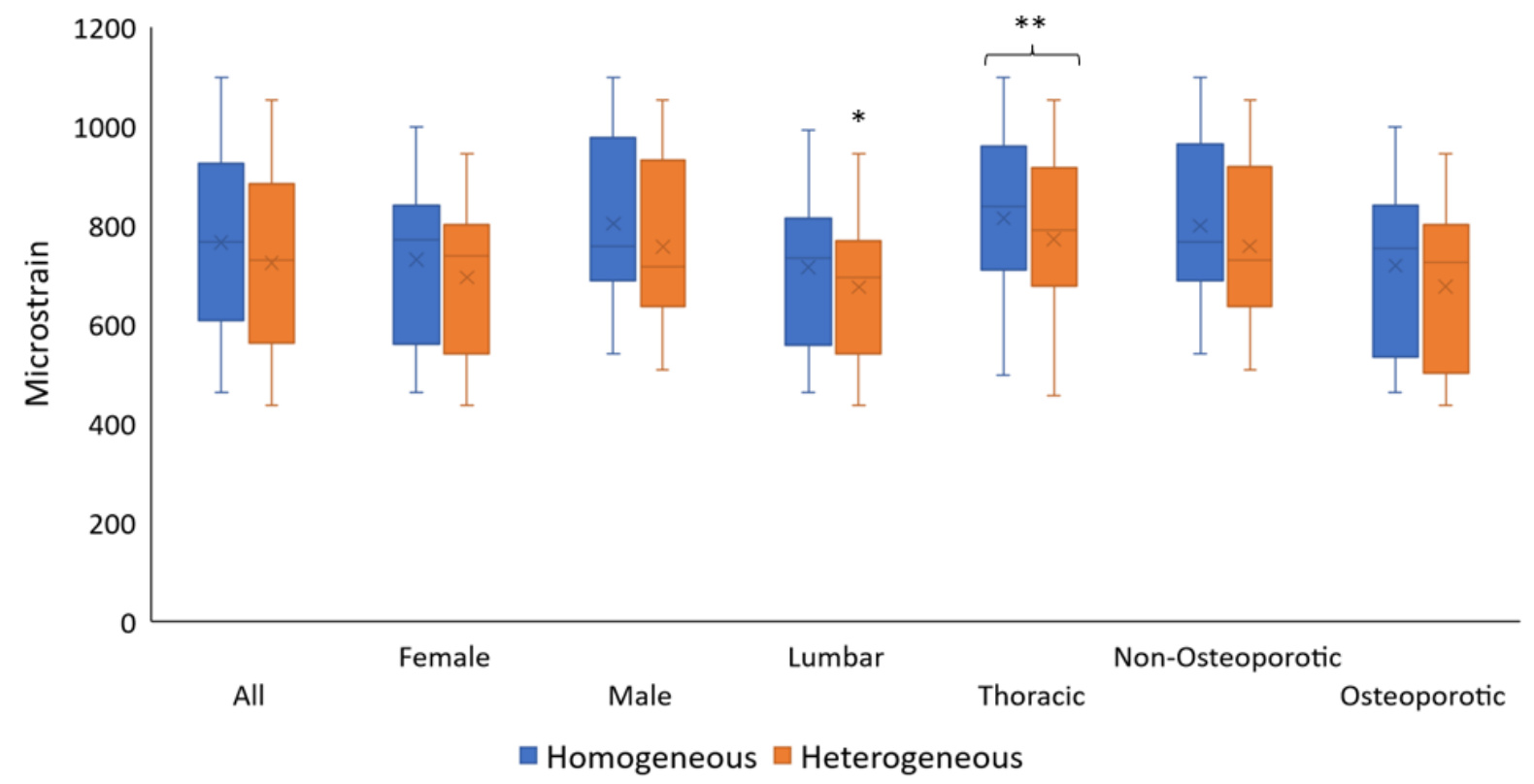

Figure 8: Absolute value of the median minimum principal strain averaged over all subjects, by sex, and by clinical bone diagnosis. ${ }^{*} p<0.05$ vs. homogeneous within lumbar group, ${ }^{* *} p<0.05$ vs. lumbar group.

transverse to the primary loading axis may play a role in preventing extreme loads from causing whole bone failure by absorbing the energy of loading through plastic buckling [54]. By comparison, bone lacking heterogeneity may also lack the ability to concentrate strain this way, reducing the efficacy of a fracture-stopping mechanism. This may also contribute to osteoporotic fracture, since osteoporosis contributes to the loss of entire trabeculae [55], as well as the homogenization of material properties [56]. While it is unclear why only lumbar models displayed this behavior, subtle differences in microarchitecture such as trabecular thickness, cross-sectional geometry, orientation, and their interactions may play a role. Further work exploring the relationship between element strain, depth from the trabecular surface, trabecular shape and orientation may further elucidate the mechanisms by which material heterogeneity impacts cancellous bone mechanics on the level of individual trabeculae.

Individuals with metabolic bone disorders such as osteoporosis are at a greater risk of fracture and may benefit most from accurate FE-based assessments of bone mechanical behavior as clinical imaging resolution improves. While previous studies have investigated the effect of low bone mass [17,57-59] or varying material distributions [36,37,39-44] in FE models, the present study aimed to elucidate how tissue material heterogeneity differentially impacts the mechanical behavior of osteoporotic and healthy bone. Our results show that, among osteoporotic subjects, models that lack specimen-specificity are poor predictors of apparent stiffness, whereas models that only lack heterogeneity do not suffer the same downside. In addition, universal homogeneous models tend to overpredict apparent stiffness in osteoporotic subjects. If used for clinical monitoring of osteoporotic fracture risk, these models would tend to artificially inflate the factor of safety for compressive fracture. These findings offer additional support that specimen-specificity is more important for improving FE-based predictions of cancellous bone mechanical behavior than heterogeneity. Though the assumption of linear behavior at the tissue level may suppress the influence of heterogeneity, it is also possible that differences in individual physiology impacting average material properties influence mechanical behavior more than variations within bone. For example, differences in bone turnover rates between individuals with osteoporosis may partially account for differences in mean tissue modulus, since greater bone turnover results in a greater quantity of osteoid, which is not fully mineralized $[8,53]$. The diagnosis of osteoporosis based on bone quantity does not capture differences in ongoing physiological processes such as bone turnover rate. This issue is highlighted by previous work showing that areal bone mineral density (aBMD) does not fully explain the variability in bone

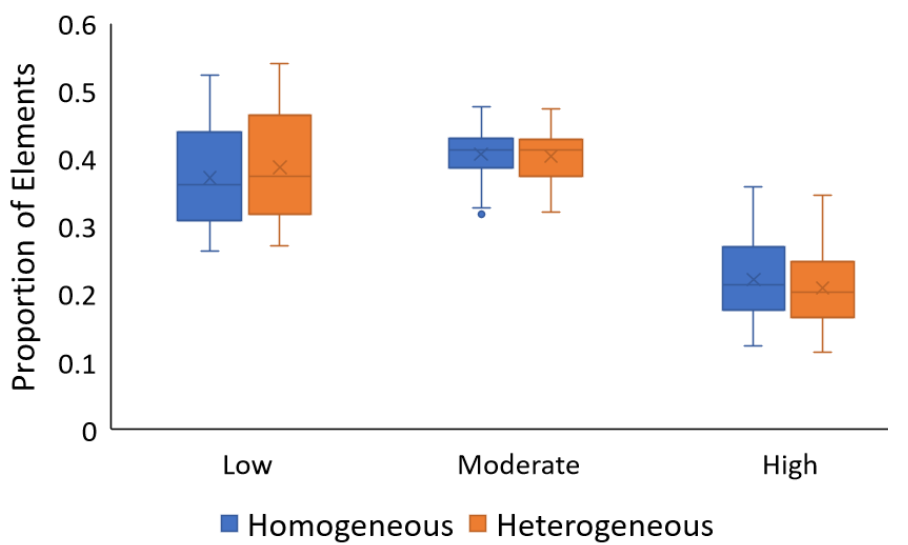

Figure 9: Percentage of elements in each minimum principal strain group (low, middle, and high strain). 
strength among osteoporotic subjects [60,61], and single-timepoint micro-CT images also suffer from an inability to investigate ongoing physiological processes. Future work employing serial micro-CT imaging compounded with image registration may therefore be able to determine the impact of variable bone turnover rate on the average material properties, bone volume fraction, and apparent modulus of cancellous bone.

The differential effect of tissue material heterogeneity between sexes is also understudied given the physiological processes of pregnancy, lactation, and menopause which contribute to changes in bone formation and resorption [62-64]. Among females, universal homogeneous models that overpredicted apparent modulus did so by an average of $62 \%$, compared to $28 \%$ for males. Specimen-specific models that overpredicted apparent modulus did so by $46 \%$ for females and $16 \%$ for males. While specimen-specific finite element models predicted similar apparent stiffness on average for males and females, adding tissue heterogeneity, whether within or between specimens, conferred greater improvements in modulus prediction for females. While the current findings support the notion that tissue material heterogeneity improves the robustness of FE-based evaluations of mechanical behavior for low-density bone and across sexes, the findings are not conclusive given the limited sample size.

Aside from the limitations inherent in a linear, single step finite element analysis, our models assumed an isotropic stiffness for all elements despite in vivo bone tissue exhibiting material anisotropy, with greater yield strain and stiffness in compression than in tension [65]. However, only an average of $0.04 \%$ of elements were in tension at $0.25 \%$ apparentlevel compression, so this limitation likely had little impact on model performance. Additionally, the findings of the present study are not directly translatable to finite element models generated by clinical computed tomography. The voxel size of clinical CT images, approximately $61 \mu \mathrm{m}$ for peripheral sites and $150 \mu \mathrm{m}$ for spine, is considerably larger than the voxels used in this study. At clinical CT resolution, the sampling of bone material properties and architectural boundaries is subject to partial volume effects, which tend to lower the apparent modulus [66]. This problem is exacerbated when modeling osteoporotic bone, in which trabecular thinning creates smaller architectural features.

In the present study of vertebral bone specimens, the mean tissue elastic modulus for heterogeneous models (14.5$22.2 \mathrm{GPa}$ ) fell within the range of mean indentation modulus in human bone tissue examined by nanoindentation (7-32 GPa) [67-69]. The range of predicted apparent stiffness from our models (0.18-0.91 GPa) did not exceed the upper range computed in previous finite element studies of human cancellous bone (1.1 GPa), but did contain lower values than previously reported $(0.42 \mathrm{GPa})[20,30,70]$. This is likely due to the substantial number of osteoporotic subjects in the present study, with experimentally measured apparent moduli as low as $0.11 \mathrm{GPa}$. Previous work investigating similar material property distributions in rabbit femora reported that specimen-specific model-predicted apparent moduli explained up to $9 \%$ more variation in experimentally measured moduli than universal models [39]. By comparison, our specimen-specific models explained 10-15\% more variation in experimentally measured moduli. The same study reported a $35 \%$ reduction in simulated apparent modulus by incorporating heterogeneous element material properties with an average COV of $26 \%$. Another study in human mandibular bone reported a $20 \%$ reduction in mean simulated apparent modulus by incorporating material heterogeneity [43]. Our results showed a mere $2 \%$ reduction in simulated apparent modulus with the same average COV in heterogeneous models. Both previous studies used small cancellous bone specimens (3-4 $\mathrm{mm}^{3}$ ) which, along with differences in species and bone site, may account for this difference. In accordance with our results, another study conducted in mandibular bone showed a $2.5 \%$ decrease in average element strain by incorporating material heterogeneity, although our results report a slightly greater decrease of $5.4 \%$.

\section{Conclusions}

Finite element models that incorporate physiological material heterogeneity generated accurate predictions of apparent modulus, which were robust to differences in sex and clinical bone status. In addition, by comparing three sets of models of increasing complexity, we determined that the average tissue mineral density of bone has a stronger influence than tissue material heterogeneity on apparent stiffness. Models that lack specimen-specific average material properties are particularly poor predictors of osteoporotic bone stiffness. While these findings help further the goal of adopting finite element models for clinical bone evaluation, the difference in imaging resolution between clinical CT and micro-CT remains a barrier and is especially limiting for osteoporotic bone. However, finite element models continue to excel at exploring the factors which govern bone mechanical behavior, a pursuit that foundationally rests on their accurate portrayal of mechanical properties. The findings presented here may help improve the accuracy of future FE-based research, particularly as it relates to osteoporotic bone. 


\section{References}

1. Beaupré GS and Hayes WC (1985) Finite element analysis of a three-dimensional open-celled model for trabecular bone. J Biomech Eng 107(3):249-56.

2. Goldstein SA (1987) The mechanical properties of trabecular bone: dependence on anatomic location and function. $J$ Biomech 20(11-12):1055-61.

3. Martin RB, Burr DB, and Sharkey NA. Skeletal Tissue Mechanics. New York: Springer, 1998.

4. Raux P, Townsend PR, Miegel R, Rose RM, and Radin EL (1975) Trabecular architecture of the human patella. J Biomech 8(1):1-7.

5. Townsend PR, Raux P, Rose RM, Miegel RE, and Radin EL (1975) The distribution and anisotropy of the stiffness of cancellous bone in the human patella. J Biomech 8(6):363-7.

6. Bourne BC, Morgan TG, Paschalis E, and van der Meulen MCH (2002) Cancellous bone anisotropy arises from both architecture and material properties. Trans Orthop Res Soc 27:558.

7. Morgan TG, van der Meulen MCH, and Bourne BC (2002) Density versus depth from trabecular surface measured by quantitative microCT. Trans Orthop Res Soc 27:110.

8. Paschalis EP, Betts F, DiCarlo E, Mendelsohn R, and Boskey AL (1997) FTIR microspectroscopic analysis of normal human cortical and trabecular bone. Calcif Tissue Int 61(6):480-6.

9. Paschalis EP, DiCarlo E, Betts F, Sherman P, Mendelsohn R, and Boskey AL (1996) FTIR microspectroscopic analysis of human osteonal bone. Calcif Tissue Int 59(6):480-7.

10. Gadeleta SJ, Boskey AL, Paschalis E, Carlson C, Menschik F, Baldini T, Peterson M, and Rimnac CM (2000) A physical, chemical, and mechanical study of lumbar vertebrae from normal, ovariectomized, and nandrolone decanoatetreated cynomolgus monkeys (Macaca fascicularis). Bone 27(4):541-50.

11. Grynpas M (1993) Age and disease-related changes in the mineral of bone. Calcif Tissue Int 53 Suppl 1:57-64.

12. Miller LM, Tibrewala J, and Carlson CS (2000) Examination of bone chemical composition in osteoporosis using fluorescence-assisted synchrotron infrared microspectroscopy. Cell Mol Biol (Noisy-le-grand) 46(6):1035-44.

13. Paschalis EP, Betts F, DiCarlo E, Mendelsohn R, and Boskey AL (1997) FTIR microspectroscopic analysis of human iliac crest biopsies from untreated osteoporotic bone. Calcif Tissue Int 61(6):487-92.

14. Beaupré GS and Hayes WC (1985) Finite element analysis of a three-dimensional open-celled model for trabecular bone. J Biomech Eng 107(3):249-56.

15. Guo XE, McMahon TA, Keaveny TM, Hayes WC, and Gibson $L$ (1994) Finite element modeling of damage accumulation in trabecular bone under cyclic loading. J Biomech 27(2):145-55.

16. Jensen KS, Mosekilde $L$, and Mosekilde $L$ (1990) A model of vertebral trabecular bone architecture and its mechanical properties. Bone 11(6):417-23.

17. Silva MJ and Gibson $\amalg$ (1997) Modeling the mechanical behavior of vertebral trabecular bone: effects of age-related changes in microstructure. Bone 21(2):191-9.

18. Yeh OC and Keaveny TM (1999) Biomechanical effects of intraspecimen variations in trabecular architecture: a threedimensional finite element study. Bone 25(2):223-8.

19. Feldkamp LA, Goldstein SA, Parfitt AM, Jesion G, and Kleerekoper M (1989) The direct examination of threedimensional bone architecture in vitro by computed tomography. J Bone Miner Res 4(1):3-11.

20. Hollister SJ, Brennan JM, and Kikuchi N (1994) A homogenization sampling procedure for calculating trabecular bone effective stiffness and tissue level stress. J Biomech 27(4):433-44.

21. Hou FJ, Lang SM, Hoshaw SJ, Reimann DA, and Fyhrie DP (1998) Human vertebral body apparent and hard tissue stiffness. J Biomech 31(11):1009-15.

22. Kabel J, Odgaard A, van Rietbergen B, and Huiskes R (1999) Connectivity and the elastic properties of cancellous bone. Bone 24(2):115-120.

23. Kabel J, van Rietbergen B, Dalstra M, Odgaard A, and Huiskes $R$ (1999) The role of an effective isotropic tissue modulus in the elastic properties of cancellous bone. J Biomech 32(7):673-80.

24. Ladd AJ, Kinney JH, Haupt DL, and Goldstein SA (1998) Finite-element modeling of trabecular bone: comparison with mechanical testing and determination of tissue modulus. J Orthop Res 16(5):622-628.

25. Niebur GL, Feldstein MJ, Yuen JC, Chen TJ, and Keaveny TM (2000) High-resolution finite element models with tissue strength asymmetry accurately predict failure of trabecular bone. J Biomech 33(12):1575-83.

26. Niebur GL, Yuen JC, Burghardt AJ, and Keaveny TM (2001) Sensitivity of damage predictions to tissue level yield properties and apparent loading conditions. J Biomech 34(5):699-706. 
27. Ulrich D, Hildebrand T, van Rietbergen B, Müller R, and Rüegsegger $P$ (1997) The quality of trabecular bone evaluated with micro-computed tomography, FEA and mechanical testing. Stud Health Technol Inform 40:97-112.

28. van Rietbergen B, Majumdar S, Pistoia W, Newitt DC, Kothari M, Laib A, and Rüegsegger P (1998) Assessment of cancellous bone mechanical properties from micro-FE models based on micro-CT, pQCT and MR images. Technol Health Care 6(5-6):413-20.

29. van Rietbergen B, Weinans H, and Huiskes R (1997) Prospects of computer models for the prediction of osteoporotic bone fracture risk. Stud Health Technol Inform 40:25-32.

30. van Rietbergen B, Weinans H, Huiskes R, and Odgaard A (1995) A new method to determine trabecular bone elastic properties and loading using micromechanical finite-element models. $J$ Biomech 28(1):69-81.

31. Goulet RW, Goldstein SA, Ciarelli MJ, Kuhn JL, Brown MB, and Feldkamp LA (1994) The relationship between the structural and orthogonal compressive properties of trabecular bone. J Biomech 27(4):375-89.

32. Hodgskinson R and Currey JD (1992) Young's modulus, density and material properties in cancellous bone over a large density range. J Mater Sci Mater Med 3(377-381)

33. Rice JC, Cowin SC, and Bowman JA (1988) On the dependence of the elasticity and strength of cancellous bone on apparent density. J Biomech 21(2):155-68.

34. Helgason, B., Perilli, E., Schileo, E., Taddei, F., Brynjólfsson, S., \& Viceconti, M. (2008). Mathematical relationships between bone density and mechanical properties: a literature review. Clin Biomech 23(2):135-146.

35. Currey, J. D. (1986). Power law models for the mechanical properties of cancellous bone. Eng in Med 15(3):153-154.

36. Jaasma MJ, Bayraktar HH, Niebur GL, and Keaveny TM (2002) Biomechanical effects of intraspecimen variations in tissue modulus for trabecular bone. J Biomech 35(2):237-46.

37. van der Linden JC, Birkenhager-Frenkel DH, Verhaar JA, and Weinans H (2001) Trabecular bone's mechanical properties are affected by its non-uniform mineral distribution. J Biomech 34(12):1573-80.

38. Homminga J, Huiskes R, van Rietbergen B, Rüegsegger $P$, and Weinans $H$ (2001) Introduction and evaluation of a grayvalue voxel conversion technique. J Biomech 34(4):513-7.

39. Bourne, B. C., \& van der Meulen, M. C. (2004). Finite element models predict cancellous apparent modulus when tissue modulus is scaled from specimen CT-attenuation. J Biomech 37(5):613-621.

40. Knowles, N. K., Ip, K., \& Ferreira, L. M. (2019). The effect of material heterogeneity, element type, and down-sampling on trabecular stiffness in micro finite element models. Ann Biomed Eng 47(2):615-623.

41. Hammond, M. A., Wallace, J. M., Allen, M. R., \& Siegmund, T. (2018). Incorporating tissue anisotropy and heterogeneity in finite element models of trabecular bone altered predicted local stress distributions. Biomech Model Mechanobiol 17(2):605-614.

42. van Ruijven, L. J., Mulder, L., \& Van Eijden, T. M. G. J. (2007). Variations in mineralization affect the stress and strain distributions in cortical and trabecular bone. J Biomech 40(6):1211-1218.

43. Renders, G. A. P., Mulder, L., Langenbach, G. E. J., Van Ruijven, L. J., \& Van Eijden, T. M. G. J. (2008). Biomechanical effect of mineral heterogeneity in trabecular bone. J Biomech 41(13):2793-2798.

44. Renders, G. A. P., Mulder, L., Van Ruijven, L. J., Langenbach, G. E. J., \& Van Eijden, T. M. G. J. (2011). Mineral heterogeneity affects predictions of intratrabecular stress and strain. J Biomech 44(3):402-407.

45. Kanis JA, Melton L, 3rd, Christiansen C, Johnston CC, and Khaltaev N (1994) The diagnosis of osteoporosis. J Bone Miner Res 9(8):1137-41.

46. Bouxsein, M. L., Boyd, S. K., Christiansen, B. A., Guldberg, R. E., Jepsen, K. J., \& Müller, R. (2010). Guidelines for assessment of bone microstructure in rodents using micro-computed tomography. J Bone Miner Res 25(7):14681486.

47. Otsu N (1979) Threshold Selection Method from Gray-Level Histograms. IEEE T Syst Man Cyb 9(1):62-66.

48. Keaveny TM, Guo XE, Wachtel EF, McMahon TA, and Hayes WC (1994) Trabecular bone exhibits fully linear elastic behavior and yields at low strains. J Biomech 27:1127-1136.

49. Hibbeler RC. Mechanics of Materials. Upper Saddle River, New Jersey: Prentice Hall, 1997.

50. Kopperdahl DL and Keaveny TM (1998) Yield strain behavior of trabecular bone. J Biomech 31(7):601-8.

51. Benjamini, Y., \& Hochberg, Y. (1995). Controlling the false discovery rate: a practical and powerful approach to multiple testing. J R Stat Soc B 57(1):289-300.

52. Odgaard, A., \& Linde, F. (1991). The underestimation of Young's modulus in compressive testing of cancellous bone specimens. Journal of biomechanics, 24(8), 691-698.

53. Mullender, M. G., \& Huiskes, R. (1995). Proposal for the regulatory mechanism of Wolff's law. Journal of orthopaedic research, 13(4), 503-512. 
54. Hayes, W. C., \& Carter, D. R. (1976). Postyield behavior of subchondral trabecular bone. J Biomed Mater Res 10(4):537544.

55. Mullender, M., Van Rietbergen, B., Rüegsegger, P., \& Huiskes, R. (1998). Effect of mechanical set point of bone cells on mechanical control of trabecular bone architecture. Bone 22(2):125-131.

56. Vennin, S., Desyatova, A., Turner, J. A., Watson, P. A., Lappe, J. M., Recker, R. R., \& Akhter, M. P. (2017). Intrinsic material property differences in bone tissue from patients suffering low-trauma osteoporotic fractures, compared to matched non-fracturing women. Bone 97:233-242.

57. Mizrahi, J., Silva, M. J., Keaveny, T. M., Edwards, W. T., \& Hayes, W. C. (1993). Finite-element stress analysis of the normal and osteoporotic lumbar vertebral body. Spine, 18(14), 2088-2096.

58. van Rietbergen, B., Huiskes, R., Eckstein, F., \& Rüegsegger, P. (2003). Trabecular bone tissue strains in the healthy and osteoporotic human femur. Journal of Bone and Mineral Research, 18(10), 1781-1788.

59. Sandino, C., McErlain, D. D., Schipilow, J., \& Boyd, S. K. (2017). Mechanical stimuli of trabecular bone in osteoporosis: A numerical simulation by finite element analysis of microarchitecture. Journal of the mechanical behavior of biomedical materials, 66, 19-27.

60. Riggs, B. L., Wahner, H. W., Seeman, E., Offord, K. P., Dunn, W. L., Mazess, R. B., ... \& Melton, L. J. (1982). Changes in bone mineral density of the proximal femur and spine with aging: differences between the postmenopausal and senile osteoporosis syndromes. The Journal of clinical investigation, 70(4), 716-723.

61. Schuit, S. C. E., Van der Klift, M., Weel, A. E. A. M., De Laet, C. E. D. H., Burger, H., Seeman, E., ... \& Pols, H. A. P. (2004). Fracture incidence and association with bone mineral density in elderly men and women: the Rotterdam Study. Bone, 34(1), 195-202.

62. Hui, S. L., Slemenda, C. W., \& Johnston, C. C. (1990). The contribution of bone loss to postmenopausal osteoporosis. Osteoporosis international, 1(1), 30-34.

63. Sowers, M., Corton, G., Shapiro, B., Jannausch, M. L., Crutchfield, M., Smith, M. L., ... \& Hollis, B. (1993). Changes in bone density with lactation. Jama, 269(24), 3130-3135.

64. Honda, A., Kurabayashi, T., Yahata, T., Tomita, M., Takakuwa, K., \& Tanaka, K. (1998). Lumbar bone mineral density changes during pregnancy and lactation. International Journal of Gynecology \& Obstetrics, 63(3), 253-258.

65. Bayraktar, H. H., Morgan, E. F., Niebur, G. L., Morris, G. E., Wong, E. K., \& Keaveny, T. M. (2004). Comparison of the elastic and yield properties of human femoral trabecular and cortical bone tissue. Journal of biomechanics, 37(1), 2735.

66. Knowles, N. K., Ip, K., \& Ferreira, L. M. (2019). The effect of material heterogeneity, element type, and down-sampling on trabecular stiffness in micro finite element models. Annals of biomedical engineering, 47(2), 615-623.

67. Donnelly E, Williams RW, Downs SA, Dickinson ME, and Baker SP (2006). Quasistatic and dynamic nanomechanical properties of cancellous bone tissue relate to collagen content and organization. J Mater Res 21:2106-2117.

68. Rho JY, Roy ME, 2nd, Tsui TY, and Pharr GM (1999). Elastic properties of microstructural components of human bone tissue as measured by nanoindentation. J Biomed Mater Res 45(1):48-54.

69. Zysset PK, Guo XE, Hoffler CE, Moore KE, and Goldstein SA (1999). Elastic modulus and hardness of cortical and trabecular bone lamellae measured by nanoindentation in the human femur. J Biomech 32(10):1005-1012.

70. van Lenthe GH, Stauber M, and Muller R (2006). Specimen-specific beam models for fast and accurate prediction of human trabecular bone mechanical properties. Bone 39(6):1182-9. 